\title{
Erkek İnfertilitesinde Antioksidanların Rolü
}

\author{
The Role of Antioxidants in Male Infertility
}

\author{
Sedat Arslan ${ }^{1}$, Aylin Ayaz ${ }^{2}$
}

Geliş tarihi/Received: 25.12.2017 • Kabul tarihi/Accepted: 10.07.2018

\section{ÖZET}

İnfertilite dünya çapında global bir sorun olmakla birlikte erkek infertilitesinin dünyadaki infertilite vakalarının yarısına yakınını oluşturduğu belirtilmektedir. İdiyopatik oligospermi (düşük sperm sayısı, spesifik tedavisi hala bilinmeyen), tam astenozoospermi (sperm motilitesinin olmaması) ve izole astenozoospermi (varikosel, enfeksiyon ya da genetik etmenler nedeniyle, düşük sperm motilitesi) gibi birçok hastalık erkek infertilitesine neden olabilir. Erkek infertilitesinde diyetle alınan besin ögelerinin ve desteklerin koruyucu etkisinin olabileceğini ve infertiliteye engel olabileceğini gösteren çalışmalar bulunmaktadır. Özellikle diyetle alınan antioksidan ögelerin ve antioksidan desteklerinin sperm kalitesi, morfolojisi, motilitesi ve sayısı üzerine olumlu etkilerinin gösterildiği çalışmalar bulunmaktadır. Ancak besin desteklerinin hangi dozda ve ne kadar süreyle kullanıldığında olumlu etki gösterdiğine dair bir rehber bulunmamaktadır. Bu derleme yazıda, erkek infertilitesinde diyetle ve besin desteğiyle antioksidan alımının etkisi incelenmiştir.

Anahtar kelimeler: Erkek infertilitesi, sağllklı beslenme, antioksidan

\begin{abstract}
Infertility is a global medical concern worldwide, and studies report that male factor infertility contributes to almost half of infertility cases globally. Several different disorders can cause male infertility, including idiopathic oligospermia (low sperm counts, for which a specific treatment remains unknown), complete asthenozoospermia (absence of sperm motility), and isolated asthenozoospermia (low sperm motility, caused by sperm dysfunction, varicocele, infection, or genetic factors). There are studies showing that in male infertility there may be protective effects of dietary sources and supplements and that even it may reverse infertility. Studies show that especially vitamin and antioxidant supplements have positive effects on sperm quality, morphology, motility and count. However, there is no guideline on the useful effect of these supplements. In this review article, the effect of dietary intake of antioxidants and antioxidant supplementation on male infertility was examined.
\end{abstract}

Keywords: Male infertility, healthy nutrition, antioxidants

1. İletişim/Correspondence: Hacettepe Üniversitesi, Sağlık Bilimleri Fakültesi, Beslenme ve Diyetetik Bölümü, Ankara, Türkiye

E-posta: sedat.arslan@hacettepe.edu.tr • $\bullet$ https://orcid.org/0000-0002-3356-7332
2. Hacettepe Üniversitesi, Sağllk Bilimleri Fakültesi, Beslenme ve Diyetetik Bölümü, Ankara, Türkiye (ㄱ) https://orcid.org/0000-0002-3543-7881 


\section{GİRIŞ}

İnfertilite, herhangi bir korunma yöntemi kullanmaksızın en az bir ylllık süre içerisinde çiftin düzenli cinsel ilişkisine rağmen gebeliğin gerçekleşmemesi durumu olarak tanımlanmaktadır (1). Ülkemizde yaklaşık olarak 1.5-2 milyon çiftin infertil olduğu tahmin edilmektedir. Gebelikten koruyucu önlem tedavisi kullanmayan fertil çiftlerin, \%20'sinde 1 ay, \%50'sinde 3 ay, \%75'inde 9 ay, \%90'ında ise 1 yll sürecinde gebelik görülmesi beklenmektedir (2). Olguların yaklaşık \%30-40’ında açıklayıcı bir infertilite nedeni bulunmamaktadır. Nedeni bilinmeyen infertilitenin yüksek prevalansının olası nedenleri Tablo 1'de gösterilmiştir (3).

Tablo 1. Nedeni bilinmeyen infertilitenin olası nedenleri (3)

\begin{tabular}{lll}
\hline Çevresel etmenler & Beslenme ve yaşam biçimi & Mesleki etmenler \\
\hline Kimyasal atıklar & Sigara-alkol-kokain vb madde bağımlılı̆̆ı & Boya ve plastik üretiminde çalışma \\
Pestisitler & Aşırı vücut ağırlığı veya zayıflık & X-ray, elektromanyetik radyasyon ve \\
Civa, kurşun, kadmiyum vb ağır & Stres & anestezik gazların etkisi altında kalmak \\
metaller, egzos gazları & Kozmetik ürünler & \\
Hava kirliliği & Uygunsuz antibiyotik kullanımı & \\
\hline
\end{tabular}

İnfertilitede bireyin sağlıklı beslenme alışkanlıklarını benimsemesi, yalnızca hastalığını ya da rahatsızlığını önlemek için değil, yeterli ve dengeli beslenme ile sağlıklı yaşamın sürdürülmesini ve günlük gereksinmesi olan besin ögelerinin alınmasını da sağlamak için önemlidir. Sağlıklı beslenmenin fertilite üzerine olan etkisini araştıran çalışmalar günden güne artmaktadır (4-6). Sağlıklı beslenme infertilitede değiştirilebilir bir risk etmeni olarak kabul edilmektedir. Sağlıklı beslenme gibi değiştirilebilir risk etmenleri yardımcı üreme teknikleri (YÜT) tedavisinin başarısında etkilidir. İnfertilitenin tedavisindeki diğer değiştirilebilir risk etmenleri ise, sigara ve alkol kullanımı ile obezitenin varlığıdır. İnfertil çiftlerin tedaviye uyum sağlamalarıyla olumlu sonuçların gözlemlenmesi mümkün olmaktadır. (7). Üreme çağındaki erkekler arasında sağlıksız beslenme alışkanlıklarının yaygın olması, özellikle diyetlerinde doymuş yağ asitleri, trans yağlar ve sodyumun yüksek, sebze ve meyvelerin (antioksidanlar ve flavonoidlerden zengin olan) ise düşük alınması, sağlık durumlarını olumsuz etkilemektedir (8).

Reaktif oksijen türleri (ROS)'un doğası ve düzeyleri ile ROS'a maruz kalma yeri ve uzunluğuna bağlı olarak ROS sperm işlevi üzerinde yararlı veya zararlı etkilere sahip olabilir. Sperm epididimal geçiş sırasında ilerleyici olarak hareket etme yeteneğini kazanır, ancak kadın kanalında "kapasite" adı verilen bir dizi fizyolojik değişiklikle dölleme yeteneğini kazanırlar (9). Fizyolojik durumlar altında, kapasitans ve akrozom reaksiyonu için gerekli olan az miktarda ROS'u spermatozoa yapar. Süperoksit anyonu bu süreçte rol oynamaktadır. Spermatozoanın oksidatif hasara duyarlı olduğu bilinmektedir çünkü plazma membranları çoklu doymamış yağ asitleri bakımından zengindir ve düşük düzeyde temizleyici enzimlere sahiptir. Farklılaşma aşamalarında erkek tohum hücrelerinin ROS üretme potansiyeline sahip olduğu bilinmektedir. Semende lökositlerden aşırı anormal spermatozoa ile aşırı ROS oluşumu infertiliteye neden olabilir (10).

Reaktif oksijen türevlerinin aşırı birikiminin sperm DNA'sı üzerinde zararlı etkileri vardır ve sperm DNA'sının temel oksidatif ürünü 8-oksodeoksiguanozinin (fragmentasyon ve mutasyona neden olan) oluşumuna yol açmaktadır. $\mathrm{Bu}$ nedenle araştırmacılar antioksidan destekleri kullanarak reaktif oksijen türlerinin sperm üzerindeki etkisini azaltma düşüncesi üzerinde durmuşlardır (11-13).

$\mathrm{Bu}$ derleme yazıda diyet, antioksidanlar ve erkek infertilitesi arasındaki ilişkinin incelenmesi amaçlanmıştır. 
Erkek İnfertilitesi ve Besin Bileşenleri Arasındaki İlişkinin Değerlendirilmesine Yönelik Yapılan Bazı Araştırmalar

Oksidatif stres, erkek infertilitesine neden olan bozuk spermatogeneze katkıda bulunmaktadır. Yapılan çalışmalarda karnitin, C ve E vitaminlerinin infertilite üzerine olumlu etkilerinin olduğu ve birinci basamak tedavide kullanılabileceği bildirilmiştir. Glutatyon, selenyum ve koenzim $Q_{10}$ gibi antioksidanların ise ikinci basamak tedavide düşünülebileceği belirtilmiştir $(14,15)$. Bununla birlikte idiyopatik erkek infertilitesinin tıbbi tedavisinde antioksidan desteğin etkinliğini ve güvenliğini belirlemek için randomize kontrollü araştırmalara gerek duyulmaktadır. Aynı zamanda her bir bileşiğin, semenin parametreleri üzerine etkilerinin ve döllenmeyi arttırmak için uygun dozun belirlenmesi gerekmektedir (16).

Erkek infertilitesi üzerine mikro besin ögelerinin etkisini saptamaya yönelik yapılan epidemiyolojik ve klinik çalışmalar Tablo 2'de verilmiştir (11,17,19,2330).

Dubai'de yapılan bir çalışmanın (17) sonuçlarına göre 2 ay süresince kullanılan C vitamini desteği (2000 mg/ gün) sonrası ortalama sperm sayısının istatistiksel olarak anlamlı oranda yükseldiği gösterilmiştir (sirasiyla 14.3×10 (6)/32.8×10 (6) sperm/mL). Ortalama sperm motilitesi $\% 43$ 'ten $\% 60.1$ 'e yükselmiş ve normal morfolojiye sahip ortalama spermler ise \%31.2'den \%66.7’ye istatistiksel ve klinik olarak anlamlı şekilde yükselmiştir. Başka bir çalışmada (18), $1.000 \mathrm{mg} \mathrm{C}$ vitamini alan grubun sperm kalitesinde istatistiksel olarak anlamlı olarak \%34 oranında iyileşme görüldüğü belirtilmiştir.

Wang ve arkadaşları (19) yaptığı çalışmada, 135 hasta randomize olarak Grup A ( $n=68)$ ve B $(n=67)$ olarak ayrılmıştır. A grubu L-karnitin (2 g/gün) ve B grubu E vitamini (2 g/gün) ile tedavi edilmiştir. Tedavi sonrası ileri hareketli sperm oranının (\%45.4) tedavi öncesine göre (\%28.6) istatistiksel olarak anlamlı derecede arttığı belirlenirken, gebelik oranı, tedaviden sonra Grup A'da (\%31.1), B’ye (\%3.8) göre anlamlı derecede yüksek bulunmuştur.
Vitali ve arkadaşları (20) yaptığı bir çalışmada, idiyopatik asthenospermisi olan 47 hastaya, 3 ay süresince $3 \mathrm{~g} /$ gün oral L-karnitin vermiştir. Tedavi edilen 47 hastanın 37'sinde (\%79), bileşiğin sperm hareketliliği ve hızlı lineer progresyonu üzerinde olumlu etkisinin olduğu, ayrıca toplam sperm sayısında da istatistiksel olarak anlamlı artış saptandığı bildirilmiştir. Randomize, plasebo kontrollü, çift kör bir çalışmada 56 gün süreyle yüksek doz oral C (1000 mg/gün) ve E (800 mg/gün) vitamini tedavisinin, infertil erkeklerin semen parametreleri üzerinde olumlu etkisinin olup olmadığı araştırılmıştır (21). Genital enfeksiyonu olmayan ancak asthenozoospermi $(<\% 50$ hareketli spermatozoa) ve normal veya sadece orta derecede azalmış sperm düzeyi ( $>7 \times 10^{6} \mathrm{sperm} / \mathrm{mL}$ ) olan hastalar incelenmiştir.Çalışmada epididimalsaklama süresinin semen parametrelerine olan etkisini araştırmak için, hastalardan vitamin tedavisinin başlamadan önce ve tedavi sonunda 2 ve 7 gün bekletme zamanı ile iki meni örneği vermeleri istenmiştir. Tedavinin sonunda semen parametrelerinde herhangi bir değişiklik gözlenmemiştir ve ek olarak gebelik gözlenmemiştir. Çalışma sonucunda $C$ ve E vitaminleri ile kombine yüksek doz antioksidan tedavinin konvansiyonel semen parametrelerini veya 24 saatlik sperm sağ kalım oranını iyileştirmediği belirlenmiştir (21).

Alizadeh ve arkadaşları (22) yaptığı 60 infertil erkek üzerinde yapılan randomize, çift kör, plasebo ve kontrollü klinik çalışmada, müdahale grubundaki bireylere 80 mg/gün kurkumin nanomicelle 10 hafta süreyle verilmiştir. Çalışmanın başlangıcında ve sonunda semen analizi, total antioksidan kapasite ve inflamatuvar belirteçler incelenmiştir. Çalışma sonunda tedavi grubundaki erkeklerin sperm sayısında, düzeyinde ve motilitesinde istastistiksel olarak anlamlı bir fark bulunmuştur. Aynı zamanda kurkumin tedavi grubunun total antioksidan kapasitesini de kontrol grubuna göre istatistiksel olarak anlamlı derece de yükseltmiştir.

Myo-inositol'ün infertilite üzerine etkilerini incelemek için yapllan in vitro çalışmada (31) myo-inositolün (2 $\mathrm{mg} / \mathrm{mL}, 2$ saat boyunca), normozoospermik 
Tablo 2. Erkek infertilitesi üzerine mikrobesin ögelerinin etkisini saptamaya yönelik yapılan epidemiyolojik ve klinik çalışmalar

\begin{tabular}{|c|c|c|c|c|}
\hline Yazar/kaynak & $\begin{array}{l}\text { Çalışma } \\
\text { şekli }\end{array}$ & $\begin{array}{l}\text { Çalışmaya } \\
\text { katılan bireyler }\end{array}$ & Vitamin/mineral alımı & Sonuçlar \\
\hline $\begin{array}{l}\text { Akmal ve arkadaşları } \\
2006 \text { (17) }\end{array}$ & $\begin{array}{l}\text { Deneysel } \\
\text { çalışma }\end{array}$ & $\begin{array}{l}13 \text { kişi } \\
\text { (25-35 yaş) }\end{array}$ & $\begin{array}{l}\text { C vitamini desteği } \\
2000 \text { mg/gün (2 ay) }\end{array}$ & $\begin{array}{l}\text { Sperm sayısı, sperm motilitesi } \\
\text { sperm morfolojisinde gelişme }\end{array}$ \\
\hline $\begin{array}{l}\text { Hammoud ve arkadaşları } \\
2012 \text { (23) }\end{array}$ & $\begin{array}{l}\text { Kesitsel } \\
\text { çalışma }\end{array}$ & $\begin{array}{l}147 \text { kişi } \\
\text { (18-67 yaş) }\end{array}$ & $\begin{array}{l}\text { Serum D vitamini düzeyleri } \\
(20 \mathrm{ng} \mathrm{mL} \leq \mathrm{D} \text { vitamini }<50 \mathrm{ng} \mathrm{mL} \text { ) }\end{array}$ & $\begin{array}{l}\text { Sperm motilitesi, morfolojisi } \\
\text { ve sayısında gelişme }\end{array}$ \\
\hline $\begin{array}{l}\text { Wang ve arkadaşları } \\
2010 \text { (19) }\end{array}$ & $\begin{array}{l}\text { Randomize } \\
\text { kontrollü }\end{array}$ & $\begin{array}{l}135 \text { kişi } \\
\text { (18-65 yaş) }\end{array}$ & $\begin{array}{l}\text { L-karnitin ve E vitamini desteği } \\
2 \text { g/gün ( } 3 \text { ay) }\end{array}$ & Sperm motilitesinde gelişme \\
\hline $\begin{array}{l}\text { Lenzi ve arkadaşları } \\
2003 \text { (24) }\end{array}$ & $\begin{array}{l}\text { Randomize } \\
\text { kontrollü }\end{array}$ & $\begin{array}{l}60 \text { kişi } \\
(20-40 \text { yaş })\end{array}$ & $\begin{array}{l}\text { L- karnitin desteği } \\
2 \text { g/gün ( } 2 \text { ay) }\end{array}$ & $\begin{array}{l}\text { Sperm düzeyinde ve } \\
\text { motilitesinde gelişme }\end{array}$ \\
\hline $\begin{array}{l}\text { Moslemi ve arkadaşları } \\
2011 \text { (25) }\end{array}$ & $\begin{array}{l}\text { Deneysel } \\
\text { çalışma }\end{array}$ & $\begin{array}{l}290 \\
(20-45)\end{array}$ & $\begin{array}{l}400 \text { IU/gün E vitamini ve } 200 \mu \text { g/gün } \\
\text { selenyum desteği (100 gün) }\end{array}$ & $\begin{array}{l}\text { Sperm motilitesi ve } \\
\text { morfolojisinde gelişme }\end{array}$ \\
\hline $\begin{array}{l}\text { Lenzi ve arkadaşları } \\
2003 \text { (24) }\end{array}$ & $\begin{array}{l}\text { Randomize } \\
\text { kontrollü }\end{array}$ & $\begin{array}{l}54 \text { kişi } \\
(>18 \text { yaş })\end{array}$ & $\begin{array}{l}400 \text { mg/gün E vitamini ve } 225 \text { g/gün } \\
\text { selenyum desteği ( } 3 \text { ay) }\end{array}$ & Sperm motilitesinde gelişme \\
\hline $\begin{array}{l}\text { Eskenazi ve arkadaşları } \\
2005 \text { (26) }\end{array}$ & $\begin{array}{l}\text { Kesitsel } \\
\text { çalışma }\end{array}$ & $\begin{array}{l}97 \text { kişi } \\
(20-80 \text { yaş) }\end{array}$ & $\begin{array}{l}\text { Diyetle yüksek C vitamini } \\
\text { (437-3394 mg), E vitamini (142-833 mg) } \\
\text { ve beta karoten (3973-33444 } \mu \mathrm{g}) \text { alımı }\end{array}$ & Yüksek sperm kalitesi \\
\hline $\begin{array}{l}\text { Wong ve arkadaşları } \\
2000 \text { (11) }\end{array}$ & $\begin{array}{l}\text { Randomize } \\
\text { kontrollü }\end{array}$ & $\begin{array}{l}211 \text { kişi } \\
(20-40 \text { yaş) }\end{array}$ & $\begin{array}{l}5 \text { mg/gün Folik asit ve } 66 \text { mg/gün } \\
\text { çinko desteği ( } 26 \text { hafta) }\end{array}$ & Sperm sayısında artış \\
\hline $\begin{array}{l}\text { Oliva ve arkadaşları } \\
2016 \text { (27) }\end{array}$ & $\begin{array}{l}\text { Deneysel } \\
\text { çalışma }\end{array}$ & $\begin{array}{l}45 \text { kişi } \\
(>18 \text { yaş) }\end{array}$ & $\begin{array}{l}\text { Andrositol (1g myoinositol, } 30 \mathrm{mg} \\
\text { L-karnitin, L-arjinin, E vitamin, } 55 \mu \mathrm{g} \\
\text { Selenyum ve } 200 \mu \mathrm{g} \text { folik asit) desteği } \\
\text { günde } 2 \text { defa ( } 3 \text { ay) }\end{array}$ & Semen parametrelerinde artış \\
\hline $\begin{array}{l}\text { Safarinejad MR } \\
2011(28)\end{array}$ & $\begin{array}{l}\text { Randomize } \\
\text { kontrollü }\end{array}$ & $\begin{array}{l}186 \text { kişi } \\
\text { (35-60 yaş) }\end{array}$ & Koenzim Q10 300 mg×2 /gün (48 hafta) & Semen parametrelerinde artış \\
\hline $\begin{array}{l}\text { Safarinejad MR } \\
2009 \text { (29) }\end{array}$ & $\begin{array}{l}\text { Randomize } \\
\text { kontrollü }\end{array}$ & $\begin{array}{l}212 \text { kişi } \\
(21-42 \text { yaş) }\end{array}$ & CoQ10 300 mg×1/gün (26 hafta) & Semen parametrelerinde artış \\
\hline $\begin{array}{l}\text { Safarinejad ve arkadaşları } \\
2012 \text { (30) }\end{array}$ & $\begin{array}{l}\text { Randomize } \\
\text { kontrollü }\end{array}$ & $\begin{array}{l}228 \text { kişi } \\
(25-44 \text { yaş) }\end{array}$ & Ubiquinol 200 mg/gün (26 hafta) & $\begin{array}{l}\text { Sperm yoğunluğu, motilitesi } \\
\text { ve morfolojisinde önemli artış }\end{array}$ \\
\hline
\end{tabular}

erkeklerden izole edilen spermatozoa'nin mitokondriyal işlevi etkilemediği, mitokondriyal membran potansiyelinin yüksek olduğu (doğurganlık potansiyelinin ölçümü) sperm sayısının ise önemli derecede arttırdığ gösterilmiştir. Bir başka in vitro çalışmada (32), 20 normozoospermik ve 20 oligoastheno-teratozoospermia hastası olan 40 erkek ile yürütülen çalışmada, myo-inositolün $(2 \mathrm{mg} / \mathrm{mL}$, 2 saat boyunca) iki grupta da sperm motilitesini arttırdığı, oligo-astheno-teratozoospermia hastalarında sperm mitokondriyal işlevi geliştirdiği gösterilmiştir.

Alfa-lipoik asit, mitokondride piruvat dehidrojenaz ve a-ketoglutarat dehidrojenaz için koenzim olarak görev yapar. Hücreler ve iç dokularda ALA, bir antioksidan olarak daha güçlü olan dihidrolipoik aside (DHLA) indirgenir. ALA veya indirgenmiş şekli olan DHLA, hem lipit hem de sulu fazlarda bir dizi oksijensiz radikal türünü söndürür, metallerle şelatlar oluşturur ve glutatyon ile etkileşimler yoluyla membran lipit peroksidasyonunu ve protein hasarını önler (33). Haghighian ve arkadaşları (34) yaptıkları randomize kontrollü çalışmada 12 hafta boyunca $600 \mathrm{mg} /$ gün ALA verilen tedavi grubunun semen parametrelerinde istatistiksel olarak anlamlı iyileşme görüldüğünü göstermişlerdir.

Randomize, plasebo-kontrollü bir çalışma da (35), 3 ay süreyle $200 \mathrm{mg} / \mathrm{gün}$ Koenzim Q10 verilen infertil erkekler de müdahale grubunda Koenzim Q10 kulanımının normal semen parametreleriyle pozitif ilişkili olduğu gösterilmiştir. 
Türk ve arkadaşlarının (36) yapmış olduğu in vitro bir çalışma da infertil erkeklerden alınan semen örnekleri incelendiğinde seminal plazmalarının antioksidan açısından tükenmiş olduğu, düşük düzeyde çinko ve selenyum minerallerini içerdiğini göstermişlerdir.

Yüksek dozda antioksidan desteğinin semen kalitesini iyileştirdiği yukarıda bahsettiğimiz birçok çalışmada gösterilmesine rağmen, infertil erkeklerde diyetle antioksidan alımı ve sperm kalitesini gösteren çalışma çok sınırlı sayıdadır ve bu çalışmalarda diyet antioksidan alımının düşük olması ile sperm kalitesinin düşük olması arasında pozitif ilişki gösterilmiştir $(37,38)$. Ancak bu gözlemsel çalışmaların çoğunda çalışmaya katılan bireyler infertil erkekler ile yapılmamıştır.

\section{SONUÇ VE ÖNERILLER}

Bu konuda yapılan çalışmalar çoğunlukla antioksidan desteklerinin sperm kalitesi üzerine etkisini incelemek üzerine yoğunlaşmıştır. Bunların büyük bir kısmında bireylere antioksidan vitamin ve minerallerin günlük önerilen diyetle alım miktarının (RDA) üzerinde miktarlar verilmiştir. Diyetle antioksidan alımı ve infertil erkeklerde sperm kalitesi ilişkisini inceleyen çalışmalar oldukça sınırlı sayıda olmakla birlikte gözlemsel ve kesitsel çalışmalardan oluşmaktadır. Ancak mevcut çalışmalar ışı̆̆ında, diyetle yeterli antioksidan alımının ya da antioksidan desteklerinin sperm morfolojisi, motilitesi ve sayısı üzerine olumlu etkilerinin olduğu belirlenmiştir. Erkek fertilitesi üzerindeetkiliolanyaşam tarzının, üremeperformansı üzerindeki olumsuz etkilerini önlemek için, çiftlere sağlıklı yaşam ve beslenme alışkanlıklarının kazandırılması ve sürdürülmesi amaçlanmalıdır. Bu doğrultuda benimsenmesi gereken multidisipliner yaklaşım içerisinde diyetisyenlerin, etkin ve nitelikli danışmanlık ve eğitim hizmetinin sürdürülmesinde önemli rol ve sorumlulukları bulunmaktadır. Erkek infertilitesinde mikro besin ögelerinden olan antioksidan vitaminlerin ve minerallerin rolü daha çok kesitsel ya da in vitro çalışmalarla araştırılmıştır. Çeşitli çalışmalarda, ROS düzeyleri subfertil hastalarda normal fertil erkeklere göre daha yüksek ve seminal antioksidan düzeylerinde anlamlı olarak daha düşük bulunmuştur. Reaktif oksijen türevleri ve erkek infertilitesinin nedenleri arasında önemli bir etmendir. Bu yüzden de bu ROS'ları temizleyici özelliği olan antioksidan özelliklere sahip besin ve besin desteklerinin erkek infertilitesinin önlenmesinde/ geriletilmesinde etkili olduğunu gösteren çalışmalar bir hayli fazladır. Ancak hangi infertilite tipinde, diyetle antioksidan alıminin ne miktarda olması gerektiği, hangi antioksidan besinlerin/desteklerin ne dozda tüketilmesi gerektiğinin tam olarak saptanabilmesi için gelecekte bu konunun daha geniş çaplı, randomize-kontrollü girişimsel araştırmalar ile desteklenmesi gerekmektedir.

Çıkar çatışması - Conflict of interest: Yazarlar çıkar çatışması olmadığın beyan ederler. - The authors declare that they have no conflict of interest.

\section{KAYNAKLAR}

1. Vayena E, Rowe PJ, Griffin PD. Current practices and controversies in assisted reproduction. Geneva: World Health Organization. 2002:15-21.

2. Aşçı R, Açıkgöz A. Varikosel: İnsidans, etiyoloji ve fizyopatoloji. Türkiye Klinikleri J Urology-Special Topics 2012;5(3):6-15.

3. Yeni E, Erel Ö, Ünal D et al. Anestezi çalişanlarinda semen analizi parametreleri ve seminal plazma oksidatif stres arasi ilişki. Turk J Urol 2004;30(1):58-62.

4. Güngör I. İnfertil çiftlerde sağllklı yaşam biçimi davranışları geliştirme ve hemşirenin rolü. İnfertilite Hemşireliği (Infertilty Nursing). İstanbul: Acar Basımevi; 2009. p.163-76.

5. Braga DP, Halpern G, Figueira RC. Food intake and social habits in male patients and its relationship to intracytoplasmic sperm injection outcomes. Fertil Steril 2012;97(1):53-59.

6. Chavarro JE, Rich-Edwards JW, Rosner BA, Willett WC. Caffeinated and alcoholic beverage intake in relation to ovulatory disorder infertility. Epidemiology 2009;20(3):374.

7. Demirci N. Erkek fertilitesi ve riskli yaşam biçimi davranışları. FNJN 2014;22(1):39-45.

8. Eslamian G, Amirjannati N, Rashidkhani B, Sadeghi MR, Hekmatdoost A. Intake of food groups and idiopathic asthenozoospermia: a case-control study. Hum Reprod 2012;27(11):3328-3336. 
9. Dacheux J-L, Dacheux F. New insights into epididymal function in relation to sperm maturation. Reproduction 2014;147:R27-R42.

10. Gharagozloo P, Aitken RJ. The role of sperm oxidative stress in male infertility and the significance of oral antioxidant therapy. Hum Reprod 2011;26:1628-1640.

11. Wong WY, Thomas CM, Merkus JM, Zielhuis GA, SteegersTheunissen RP. Male factor subfertility: possible causes and the impact of nutritional factors. Fertil Steril 2000;73(3):435-442.

12. Mora-Esteves C, Shin D. Nutrient supplementation: improving male fertility fourfold. Semin Reprod Med 2013;31:293-300.

13. Mostafa T, Anis T, Imam H, El-Nashar AR, Osman IA, et al. Seminal reactive oxygen species-antioxidant relationship in fertile males with and without varicocele. Andrologia 2009;41:125-129

14. Balercia G, Mancini A, Tirabassi G, Pontecorvi A. Coenzyme Q10 in male infertility, in antioxidants in andrology. Cham: Springer International Publishing; 2017. p.43-57.

15. Vahidinia A, Rahbar AR, Shakoori M, Mohammad M. Effect of astaxanthin, vitamin $\mathrm{E}$, and vitamin $\mathrm{C}$ in combination with calorie restriction on sperm quality and quantity in male rats. J Diet Suppl 2016:1-12.

16. Agarwal A, Sekhon LH. The role of antioxidant therapy in the treatment of male infertility. Hum Fertil (Camb) 2010;13(4):217-225.

17. Akmal M, Qadri JQ, Al-Waili NS. Improvement in human semen quality after oral supplementation of vitamin C. J Med Food 2006;9(3):440-442.

18. Dawson EB, Harris WA, Teter MC, Powell LC. Effect of ascorbic acid supplementation on the sperm quality of smokers. Fertil Steril 1992;58(5):1034-1039.

19. Wang YX, Yang SW, Qu CB. L-carnitine: safe and effective for asthenozoospermia. National Journal of Andrology 2010;16(5):420-422.

20. Vitali G, Parente R, Melotti C. Carnitine supplementation in human idiopathic asthenospermia: clinical results. Drugs Exp Clin Res 1994;21(4):157-159.

21. Rolf C, Cooper TG, Yeung CH, Nieschlag E. Antioxidant treatment of patients with asthenozoospermia or moderate oligoasthenozoospermia with high-dose vitamin $\mathrm{C}$ and vitamin $\mathrm{E}$ : a randomized, placebocontrolled, double-blind study. Hum Reprod 1999;14(4):1028-1033.

22. Alizadeh F, Javadi M, Karami AA, Gholaminejad F, Kavianpour M, Haghighian HK. Curcumin nanomicelle improves semen parameters, oxidative stress, inflammatory biomarkers, and reproductive hormones in infertile men: A randomized clinical trial. Phytother Res 2018;32(3):514-521.
23. Hammoud AO, Meikle AW, Peterson CM. Association of 25-hydroxy-vitamin D levels with semen and hormonal parameters. Asian J Androl 2012;14(6):855-859.

24. Lenzi A, Lombardo F, Sgrò P. Use of carnitine therapy in selected cases of male factor infertility: a double-blind crossover trial. Fertil Steril 2003;79(2):292-300.

25. Mohammad K, Moslemi ST. Selenium-vitamin E supplementation in infertile men: effects on semen parameters and pregnancy rate. IJGMP 2011;4:99-104.

26. Eskenazi B, Kidd SA, Marks AR. Antioxidant intake is associated with semen quality in healthy men. Hum Reprod 2005;20(4):1006-1012.

27. Montanino Oliva M, Minutolo E, Lippa A, Iaconianni P, Vaiarelli A. Effect of myoinositol and antioxidants on sperm quality in men with metabolic syndrome. Int J Endocrinol 2016;2016:1674950.

28. Safarinejad MR. Safety and efficacy of coenzyme Q10 supplementation in early chronic Peyronie's disease: a double-blind, placebo-controlled randomized study. Int J Impot Res 2010;22(5):298-309.

29. Safarinejad MR. Efficacy of coenzyme Q10 on semen parameters, sperm function and reproductive hormones in infertile men. J Urol 2009;182(1):237-248.

30. Safarinejad MR, Safarinejad S, Shafiei N, Safarinejad S. Effects of the reduced form of coenzyme Q 10 (ubiquinol) on semen parameters in men with idiopathic infertility: a double-blind, placebo controlled, randomized study. J Urol 2012;188(2):526-S31.

31. Condorelli RA, La Vignera S, Di Bari F, Unfer V, Calogero AE. Effects of myoinositol on sperm mitochondrial function in-vitro. Eur Rev Med Pharmacol Sci 2011;15(2):129-134.

32. Condorelli RA, La Vignera S, Bellanca S, Vicari E, Calogero AE. Myoinositol: does it improve sperm mitochondrial function and sperm motility? J Urol 2012;79(6):12901295.

33. Ali YF, Desouky OS, Selim NS, Ereiba KM. Assessment of the role of a-lipoic acid against the oxidative stress of induced iron overload. J Radiat Res Appl Sci 2015;8:2635.

34. Haghighian HK, Haidari F, Mohammadi-Asl J, Dadfar M. Randomized, triple-blind, placebo-controlled clinical trial examining the effects of alpha-lipoic acid supplement on the spermatogram and seminal oxidative stress in infertile men. Fertil Steril 2015;104(2):318-324.

35. Nadjarzadeh A, Shidfar F, Amirjannati N, Vafa MR, Motevalian SA, Gohari MR, et al. Effect of Coenzyme Q10 supplementation on antioxidant enzymes activity and oxidative stress of seminal plasma: a double-blind randomised clinical trial. Andrologia 2014;46(2):177183.

36. Türk S, Mändar R, Mahlapuu R, Viitak A, Punab 
M, Kullisaar T. Male infertility: decreased levels of selenium, zinc and antioxidants. J Trace Elem Med Biol 2014;28(2):179-185.

37. Mendiola J, Torres-Cantero AM, Vioque J, Moreno-Grau JM, Ten J, Roca M. A low intake of antioxidant nutrients is associated with poor semen quality in patients attending fertility clinics. Fertil Steril 2010;93(4):11281133.

38. Nadjarzadeh A, Mehrsari A, Mostafavi E, Gohari MR, Shidfar F. The association between dietary antioxidant intake and semen quality in infertile men. Med J Islam Repub Iran 2013;27(4):204-249. 